\section{EDUCAÇÃO FÍSICA ESCOLAR EM TEMPOS DE DISTANCIAMENTO SOCIAL: PANORAMA, DESAFIOS E ENFRENTAMENTOS CURRICULARES}

SCHOOL PHYSICAL EDUCATION IN TIMES OF SOCIAL DISTANCING:
OVERVIEW, CHALLENGES AND CURRICULUM ISSUES C?

EDUCACIÓN FÍSICA ESCOLAR EN TIEMPOS DE DISTANCIA SOCIAL: PANORAMA GENERAL, DESAFÍOS Y ENFOQUES CURRICULARES C

doi' https://doi.org/10.22456/1982-8918.106233

(iD) Roseli Belmonte Machado*<robelmont@yahoo.com.br>

Denise Grosso da Fonseca* <dgf.ez@terra.com.br>

Francine Muniz Medeiros*<franphone1@hotmail.com>

Nícolas Fernandes* <fernandesnicolas.nf@gmail.com>

*Universidade Federal do Rio Grande do Sul. Porto Alegre, RS, Brasil.
Resumo: $O$ ano de 2020 trouxe a pandemia de Covid-19, atingindo o mundo. As medidas de contenção da propagação incluíram o distanciamento social, provocando, em meados de março de 2020, o fechamento das escolas, o que ocasionou o deslocamento de aulas presenciais para remotas. A partir disso, objetivamos compreender o modo como a Educação Física, no Rio Grande do Sul, tem se posicionado no cenário das aulas remotas. Realizamos uma pesquisa de abordagem qualitativa com professores que atuam em escolas do Rio Grande do Sul e estão trabalhando com Educação Física pelo ensino remoto. O instrumento foi um questionário com 20 perguntas enviado por e-mail. Percebemos que a Educação Física acompanhou as atividades produzidas pelas escolas, mas identificamos alterações na forma de condução e ressaltamos os desafios do trabalho dos docentes e seus efeitos no currículo.

Palavras chave: Educação Física. Infecções por coronavírus. Professores Escolares. Currículo.
Recebido em: 07-08-2020 Aprovado em: 12-10-2020 Publicado em: 08-12-2020

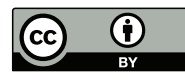

Este é um artigo publicado sob a licença Creative Commons Atribuição 4.0 Internacional (CC BY 4.0). eISSN: $1982-8918$ 


\section{CENÁRIOS}

O ano de 2020 trouxe a pandemia de Covid-19, que se constituiu em uma das maiores crises sanitárias a atingir o mundo neste início de século. Todos foram impactados por uma situação cujas consequências nefastas nenhum país, mesmo os chamados desenvolvidos, se mostrava preparado para enfrentar, com alguma garantia de sucesso.

Uma análise do contexto no qual se instala tão brutal ameaça revela o quadro de vulnerabilidade do ser humano, em uma conjuntura em que a natureza se encontra devastada; a desigualdade social se aprofunda e se amplia em dimensões imensuráveis; o individualismo e a competição exacerbados promovem o alastramento da exclusão e desumanização nas relações sociais; os países que detêm maior condição econômica pautam seus embates na busca de mais poder, abandonando qualquer indício de solidariedade em nome de um bem comum. No Brasil, há não apenas uma crise na saúde, mas também uma crise política, que agrava o quadro epidemiológico por conta dos equívocos no tratamento dispensado a essa pandemia pelo Governo Federal.

Contudo, algumas medidas foram tomadas por estados e municípios. Dentre elas, no Rio Grande do Sul, houve a determinação de um distanciamento social, que teve efeitos em distintos setores e instituições. Nesse panorama, encontram-se as instituições escolares, que foram fechadas em meados de março de 2020, parando suas atividades presenciais.

A partir da Medida Provisória 934 , do Ministério da Educação, que "estabelece normas excepcionais sobre o ano letivo da educação básica e do ensino superior decorrentes das medidas para enfrentamento da situação de emergência de saúde", as escolas deram continuidade ao ensino de forma remota. Nesse contexto, está a Educação Física, fato que instiga esta investigação, a qual está inserida em uma pesquisa já em andamento e aprovada em comitê de pesquisa ${ }^{2}$, com o objetivo de compreender o modo como a Educação Física Escolar no Rio Grande do Sul tem se posicionado no cenário das aulas remotas em tempos de distanciamento social frente à pandemia de Covid-19.

Como forma de apresentar a pesquisa, este artigo tem cinco partes subsequentes: as escolhas metodológicas, com os caminhos de pesquisa e a perspectiva conceitual; duas seções do referencial que sustenta a pesquisa; uma seção que discute os principais pontos evidenciados na pesquisa; e, para finalizar, algumas considerações.

\section{ESCOLHAS METODOLÓGICAS}

A escolha dos caminhos para chegar à pesquisa tem relação com o foco proposto na discussão, dentro de uma abordagem qualitativa. Optar por um estudo

1 Disponível em: http://www.in.gov.br/en/web/dou/-/medida-provisoria-n-934-de-1-de-abril-de-2020-250710591. Acesso em: 30 de maio de 2020.

2 Aprovada e registrada no Comitê de Ética em Pesquisa da Universidade Federal do Rio Grande do Sul. 
dessa natureza, para Gatti e André (2013), diz respeito a um mergulho em situações em que são produzidos os sentidos e significados do que se procura conhecer, buscando uma compreensão que aproxime o real e as formas de representação e ação. Tal perspectiva procura atender "ao desafio da compreensão dos aspectos formadores/ formantes do humano, de suas relações e construções culturais, em suas dimensões grupais, comunitárias ou pessoais" (GATTI; ANDRÉ, 2013, p. 30). Considera-se que o olhar sob um desenho qualitativo traz a possibilidade de compreender o momento educacional atual.

Realizou-se um estudo de cunho exploratório junto a professores de Educação Física que estivessem atuando nas escolas gaúchas no momento do distanciamento social. O contato foi sistematizado pelo uso de um questionário composto por 20 questões, abertas e fechadas, elaborado na plataforma Google - Google Forms. Foram temas das questões: a participação da Educação Física nas aulas remotas; o uso das plataformas digitais; a condução das aulas de Educação Física; dificuldades dos docentes; planejamento e avaliação; atividades e conteúdos desenvolvidos; a Educação Física e suas relações com a Área das Linguagens e com a BNCC; trabalho com alunos considerados de inclusão.

A escolha dos sujeitos seguiu dois critérios: 1) ser professor que atua na Educação Básica em escolas gaúchas das diferentes redes; 2) estar trabalhando com Educação Física Escolar no momento de distanciamento social. Para atender aos critérios, foram convidados professores que participaram de curso de extensão para formação docente na universidade ${ }^{3}$. Na sequência, a pesquisa também foi divulgada em redes sociais, destacando os critérios dos sujeitos que poderiam participar, acompanhados de termo de adesão com cuidados éticos. Todos os questionários estão de posse dos pesquisadores e comprovam atenção aos critérios da pesquisa. O questionário foi enviado aos participantes e divulgado nas redes sociais em $1^{\circ}$ de maio de 2020. As respostas foram recebidas até 10 de maio de 2020.

Foram recebidos 43 formulários. Desses, 11 foram de professores que atuam na rede estadual de ensino, 12 de professores que atuam em escolas privadas e 20 de professores que atuam nas redes municipais de 15 cidades gaúchas. Os professores trabalham com o ensino fundamental, o ensino médio e a educação infantil.

A análise está baseada na perspectiva dos estudos educacionais pósestruturalistas. Compreende-se que as relações entre saber e poder constituem subjetividades e identidades, que o poder é relacional, que os mecanismos de regulação e controle estão dispersos no tecido social e que a escola é um desses dispositivos, sendo central na tarefa de normalização, disciplinarização, regulação e governo das pessoas e das populações (SILVA, 1994). Entende-se que pesquisar a partir desse modo de olhar contribui para compreensão dos processos de produção e constituição da Educação Física Escolar e da docência nestes tempos. Antes de propor modos de fazer ou de apontar verdades, certezas ou erros, é preciso entender como esses processos estão se desenvolvendo e quais são os seus efeitos na constituição dos sujeitos. Trata-se de uma filosofia que permite refletir sobre os 
acontecimentos atuais e também compreende a genealogia dos processos tomados como verdadeiros. Para o empreendimento analítico, retomou-se a constituição pedagógico-legislativa da Educação Física Escolar, aprofundando-se a noção de currículo, conforme apresentado a seguir.

\section{ASPECTOS LEGISLATIVOS E PEDAGÓGICOS DA EDUCAÇÃo FÍSICA}

As questões legislativas e pedagógicas têm se constituído em esteira importante enquanto artefatos normatizadores do ensino desenvolvido nas escolas. Em referência às Leis de Diretrizes e Bases da Educação Nacional, desde a primeira, divulgada em 1961, a presença da Educação Física é colocada como obrigatória nos currículos escolares, perpassada por diferentes identidades, que se alteram, na medida em que concepções epistemológicas e pedagógicas, bem como interesses políticos e econômicos, postulam distintas ênfases para seu ensino, além de seu posicionamento na organização curricular.

Na LDB 4024/1961, a Educação Física teve sua obrigatoriedade estendida a todos os níveis e ramos de ensino, com predominância esportiva na Educação Superior. Já na década de 1970, a LDB 5.692/1971 (BRASIL, 1971ª) e o Decreto 69450/1971 (BRASIL, 1971b) determinam, respectivamente, a integração ao currículo como atividade escolar regular e a aptidão física como referência para o planejamento, controle e avaliação. Na sequência, a LDB 9394/1996 (BRASIL, 1996) estabelece que a Educação Física passe a ser componente curricular obrigatório da Educação Básica, integrada à proposta pedagógica da escola. Tal versão da LDB, a partir da Lei 13.415/2017 (BRASIL, 2017), diante de uma reforma curricular para o ensino médio, estabelece que esse nível de escolaridade, a partir da Base Nacional Comum Curricular (BNCC), incluirá, obrigatoriamente, estudos e práticas de Educação Física, Arte, Sociologia e Filosofia. As condições de estudos e práticas, bem como as alterações que vinham sendo propostas desde a MP 746/2016, posteriormente sancionadas pela lei 13.415/2017, foram explicadas por Maria Helena Guimarães de Castro, uma das responsáveis pela reforma do ensino médio. Sobre o caráter obrigatório ou não desses componentes, declara:

\footnotetext{
Não é o componente curricular dessas disciplinas que é obrigatório e, sim, o ensino de Sociologia, Filosofia, Educação Física e Arte em atividades que podem ser dentro de uma disciplina específica ou em projeto interdisciplinar (CASTRO, 2017).
}

Tal perspectiva retira a possibilidade de aprofundamento do conjunto de conhecimentos dos referidos componentes e, no caso da Educação Física, a relega, mais uma vez, ao caráter de atividade, provocando um reposicionamento curricular. Em um retrospecto do percurso da Educação Física no âmbito legislativo nas últimas cinco décadas, é possível ver um avanço na dimensão pedagógica e curricular a partir da década de 1990, decorrente de sua identificação como componente curricular obrigatório. Entretanto, tal avanço fica comprometido quando essa condição deixa de ser estendida ao ensino médio, comprometendo a possibilidade de uma formação integral, aspecto defendido nas Diretrizes Curriculares Nacionais. 
$\mathrm{Na}$ conjuntura que instiga esta pesquisa, esta é uma questão a ser constatada: em plena pandemia, em que o distanciamento social nos desafia a encontrar novas formas de sobrevivência e sociabilização, bem como de boa ocupação do maior tempo disponível e do espaço, configurado a partir de sérias restrições, as atividades culturais, artísticas e relacionadas às práticas corporais passam a ser solicitadas e valorizadas quase como garantia de vida, com alguma qualidade, para as pessoas.

No atual contexto, a BNCC foi analisada, buscando-se integrá-la aos demais artefatos que ajudam a compor o currículo das escolas brasileiras, apesar dos muitos questionamentos acerca do modo como foi produzida e da pouca profundidade dada à sua versão final, que desconsiderou o processo de escuta e coparticipação de distintas instâncias e instituições ligadas à educação no país, o que, em consequência, traz limitações na versão relativa ao ensino médio. A Educação Física é reafirmada na BNCC como constituinte da Área das Linguagens, em articulação com Língua Portuguesa, Arte e Língua Inglesa. Nessa perspectiva, "tematiza as práticas corporais em suas diversas formas de codificação e significação social, entendidas como manifestações das possibilidades expressivas dos sujeitos, produzidas por diversos grupos sociais no decorrer da história" (BRASIL, 2018, p. 213).

A Educação Física, em que pesem as questões legislativas e pedagógicas que a constituem, nos dias de hoje, é um componente curricular que visa ao trabalho das múltiplas práticas corporais, balizadas por seus aspectos históricos, sociais e culturais. Portanto, na perspectiva deste estudo, não está fora das operações/ relações de poder que a perpassam.

\section{EDUCAÇÃO FÍSICA ESCOLAR E CURRÍCULO}

Refletir sobre os aspectos legislativos e pedagógicos da Educação Física Escolar, considerando, de certo modo, a que serviam, conduz a pensar sobre currículo. As escolhas "do que ensinar" e "de como ensinar" refletem os posicionamentos subjacentes ao projeto educativo conduzido. Nessa perspectiva, quando se fala em currículo, é para além da organização curricular, tendo em vista o que envolve o ser e o estar do espaço escolar e os efeitos disso na constituição dos distintos sujeitos.

Abordar conteúdos e metodologias permite pensar sobre organização curricular, mas também sobre o tema do currículo, uma vez que este está articulado com as escolhas diárias dentro do espaço escolar. A noção de currículo é compreendida a partir de autores de uma vertente pós-estruturalista de pensar a educação, o que leva a relacionar o currículo a uma operação saber-poder-verdade. Para Silva (2001), as verdades e o próprio currículo são construções que atendem a uma época e a uma finalidade e que, em boa medida, são atreladas a relações de poder. Selecionar é uma operação de poder. Privilegiar um tipo de conhecimento é uma operação de poder. Quando se escolhe uma organização curricular, se diz sobre o currículo de determinada instituição, sobre quais sujeitos se quer constituir, sobre qual verdade é a escolhida; enfim, se esclarece sobre os saberes que subsidiam as escolhas, e todas essas operações são operações de poder. 
Veiga-Neto (2014) destaca que o currículo não deve ser entendido e problematizado em uma dimensão reduzida à epistemologia tradicional ou restrita a qualquer ideologia, seja ela de matriz política, econômica, cultural ou filosófica. Em suas palavras: "Ele deve ser pensado a partir de complexas miradas sobre o social; miradas ao mesmo tempo panorâmicas e focais, abrangentes e específicas, disciplinares e transdisciplinares, macroscópicas e microscópicas" (VEIGANETO, 2014, p. 1). Assim, ao olhar para as práticas da Educação Física, é preciso problematizar que são feitas escolhas, implicadas em relações saber-poder-verdade, que compõem o currículo e provocam efeitos sobre os sujeitos.

Salienta-se a compreensão de prática a partir de uma perspectiva foucaultiana. Segundo Veyne, "[...] a prática não é uma instância misteriosa, um subsolo da história, um motor oculto: é o que fazem as pessoas [...]" (VEYNE, 1995, p 157). Prática, nesta pesquisa, refere-se às atividades realizadas pelos professores independentemente de seu caráter, forma e modelo ou da capacidade de propiciar maior ou menor amplitude de movimento aos estudantes.

No apanhado de práticas da Educação Física Escolar no Brasil, pode-se afirmar que, no início do século XX, a Educação Física era constituída por práticas marcadas por instruções militares, por disciplina, pela higiene dos corpos e pelo reforço da saúde física e moral. Esteve associada ao desenvolvimento da medicina social, servindo a uma necessidade de higienização, disciplinamento e regeneração da raça e também enaltecendo o despertar do gosto pelo esforço esportivo e atlético como um hábito de vida capaz de opor-se a um modo de condução prejudicial do fisiológico, do moral e do social. Entrou na escola referendada pela Constituição Federal Brasileira de 1937 (BRASIL, 1937) para preparar a juventude para o cumprimento dos seus deveres com a economia e a defesa da nação. No período posterior à Segunda Guerra Mundial, compreendido entre 1945 e 1964, houve um encontro da Educação Física com a Pedagogia, já iniciado com o advento do Movimento da Escola Nova, fazendo com que iniciasse um grande processo de pedagogização das práticas esportivas. A seguir, no bojo de uma ditadura militar do governo brasileiro, há uma Educação Física marcada por vontade de disciplina, ordem, moral e nacionalidade (MACHADO, 2016).

A partir da década de 1980, muitos autores escrevem sobre como a Educação Física deveria ser, apresentando críticas aos modelos precedentes. Destaca-se a obra Metodologia do Ensino da Educação Física (CASTELLANI FILHO et al., 1992), em que a Educação Física é uma disciplina que trata, pedagogicamente, na escola, do conhecimento de uma área chamada de cultura corporal. Essa compreensão amplia-se e começa a habitar documentos pedagógicos, como é o caso dos PCNs, que orientam a elaboração de documentos escolares.

Recentemente, como já sinalizado, as instituições começaram a vivenciar práticas a partir da BNCC, balizadas por uma ideia de competências. Muitos autores discutem que o cenário educacional, em que habita a ideia de competência, também está ligado à lógica de gerenciamento, de adoção de índices econômicos como indicadores de qualidade, dos rankings de desempenho e da meritocracia. Para Saraiva e Veiga-Neto (2009), no modelo de ensino por competência, o docente é visto como "gestor de competências", sendo um sujeito encarregado de planejar, 
executar e avaliar determinados programas, com o objetivo de atingir certos resultados, esperados a priori. Isso era o que começávamos a viver. Em que pese a BNCC ter trazido a legitimação de importantes saberes que começavam a constituir a Educação Física Escolar, também estava engendrada na perspectiva de um jogo neoliberal, vinculando o currículo a essa forma.

Estas reflexões são importantes para que, ao compreender como a Educação Física se estabelecia, como os currículos foram sendo produzidos e os possíveis efeitos nos sujeitos, seja possível refletir sobre as práticas nestes tempos de distanciamento social.

\section{EDUCAÇÃO FÍSICA ESCOLAR E O DISTANCIAMENTO SOCIAL}

Ao problematizar os aspectos pedagógicos, legislativos e curriculares da Educação Física no Brasil, busca-se conhecer a situação deste componente curricular frente à situação de distanciamento social decorrente da pandemia de Covid-19. Para isso, inicia-se pelo relato das práticas em três situações: quais saberes estão sendo trabalhados, qual metodologia é utilizada e como chegam até os alunos.

Sobreossaberestrabalhados, comoum mododeapresentá-loscategoricamente, foi usada a organização presente no Referencial Curricular Lições do Rio Grande - Linguagens, Códigos e suas Tecnologias (RIO GRANDE DO SUL, 2009) como inspiração. Nesse referencial, os saberes são divididos em saberes conceituais e corporais. Saberes conceituais seriam o "conjunto de dados e conceitos que descrevem e explicam diferentes aspectos relativos às práticas corporais sistematizadas" (RIO GRANDE DO SUL, p. 119), e saberes corporais seriam "os saberes que se produzem/constroem com base na experiência sustentada predominantemente no movimento corporal" (RIO GRANDE DO SUL, p. 119). Ainda, na categorização, foram acrescentados saberes atitudinais, considerando-se as aprendizagens de cunho ético, moral e estético, construídos a partir das vivências com os saberes corporais e conceituais estabelecidos nas/a partir das relações e interações entre os sujeitos nas aulas. Ressalta-se que, como toda divisão e categorização, essa escolha não dará conta de todas as realizações de uma prática, mas serve como modo didático de explicar os achados desta pesquisa e de ilustrar as práticas.

A análise mostra que os professores propuseram, inicialmente, levar saberes conceituais aos seus alunos. A exemplo, temos a análise histórica das práticas corporais; regras de execução das diferentes práticas corporais; conhecimento sobre federações e organizações esportivas; relações culturais das práticas corporais; conhecimento sobre o corpo, saúde, exercícios, atividade física etc. Com o desenrolar das aulas de forma remota, os professores passaram a conduzir saberes corporais, ensinando e conduzindo a execução de procedimentos; provocando os alunos a movimentar-se; realizando um jogo ou brincadeira; vivenciando uma modalidade de dança; executando um movimento da ginástica; sentindo um movimento de uma luta; realizando o fundamento de algum esporte; etc. Houve um deslocamento - início com foco em saberes conceituais e avanço para saberes corporais, mantendo uma relação com as escolhas metodológicas que foram feitas. 
Sobre a metodologia, duas questões tiveram influência: o tipo de saber trabalhado - se conceitual ou corporal - e a possibilidade oportunizada pela instituição para que esse saber chegasse aos alunos - quais meios foram utilizados. Identificase como opção metodológica o envio de materiais de leitura - digitais ou impressos -, atividades de análise e reflexão sobre esses textos e indicação de vídeos. Com o desenvolvimento do ensino remoto, assim como os saberes se deslocaram, outras metodologias começaram a ser organizadas pelos docentes: produção de videoaulas, realização de aulas síncronas, organização de salas de debate, proposta e execução de diferentes movimentos referentes a práticas corporais. Nota-se uma mudança nas opções metodológicas a partir do momento em que houve uma mudança de ênfase do trabalho dos saberes conceituais para os saberes corporais.

Sobre como os saberes chegaram aos alunos, sobressai o uso das tecnologias de informação e de comunicação. A primeira ferramenta foi o aplicativo de rede social WhatsApp, muito utilizado, tanto para envio dos materiais, quanto para comunicação e dúvidas. Além desse, destacam-se a página da rede social Facebook das escolas, os websites das escolas, o aplicativo Instagram, os provedores de e-mail e as plataformas, como Google Meet, Google Classroom, Zoom, Skype e outras. Ainda outro meio foi a entrega e retirada de materiais pelos alunos: os alunos ou suas famílias vão até a escola, retiram materiais desenvolvidos pelos professores, levam para casa e fazem as tarefas. Isso é devolvido para as escolas, e os professores buscam, corrigem e dão feedback aos alunos. Muitas instituições e docentes lançaram mão dessas ferramentas de forma conjunta para tentar atingir a multiplicidade de alunos, considerando: condições de acesso, condições familiares e necessidades de estímulos diversos para aprendizagem. Também vale destacar que, por diferentes situações, muitas instituições não estão desenvolvendo o ensino remoto, mas mantêm contato com os alunos e as famílias.

Sublinha-se que esse processo não é o chamado homeschooling ${ }^{4}$, embora, a partir de um senso comum, muitas pessoas o nomeiem desse modo. O que temos é um conjunto de saberes selecionados, pensados e organizados pelas instituições escolares e pelos professores e então levados até os alunos. Há o trabalho do professor e de uma instituição para chegar aos alunos. Professores e alunos habitam espaços diferentes - cada um em sua casa - e tempos diferentes - nem sempre as aulas são síncronas -, mas, ainda assim, possuem vínculo.

A partir desse panorama, destacam-se duas categorias que foram sistematizadas na análise, nomeadas de "Desafios da Educação Física no Ensino Remoto" e "Enfrentamentos e possibilidades", abordadas nas seções que seguem.

\subsection{DESAFIOS DA EDUCAÇÃO FÍSICA NO ENSINO REMOTO}

Nesta seção, são apresentados os principais desafios dos docentes no ensino remoto. De um modo geral, é possível dizer que, no tocante ao desenvolvimento das aulas de Educação Física nas instituições públicas, os professores que atuam nessas

\footnotetext{
4 A educação domiciliar ou homeschooling é a substituição integral da frequência à escola pela educação doméstica e a responsabilidade pela educação formal dos filhos é atribuída aos próprios pais ou responsáveis. Disponível em: https://desafiosdaeducacao.grupoa.com.br/educacao-domiciliar-pandemia/ Acesso em: 20 jul. 2020.
} 
escolas sempre apresentaram dificuldades de distintas ordens. Neste período, as dificuldades permanecem, porém com outras características, como, por exemplo, o acesso à internet e o tempo de planejamento, já que a escola invadiu suas casas. Oliveira (2004) já apontava que os professores são pressionados a cumprirem novas exigências pedagógicas e administrativas, mas falta-lhes estrutura adequada, o que implica processos de precarização do trabalho docente. Dentre as dificuldades que os professores estão enfrentando neste período de distanciamento social, salientam-se: o desconhecimento e falta de acesso a tecnologias da informação e da comunicação, a valorização de saberes corporais em detrimento de outros e a falta de interação.

Em primeiro lugar, o uso da tecnologia nas salas de aula, assunto que há algum tempo vem sendo discutido, intensificou-se para mediar o processo de ensino remoto. Considerando os dados da Agência Brasil (2020a), um a cada quatro brasileiros não tem acesso à internet, o que, em números totais, representa cerca de 46 milhões. Falam os professores:

\footnotetext{
Acesso dos alunos às plataformas, contato direto... É difícil conseguir que as famílias se organizem para os encontros em tempo real, de forma online. (Professor 5).

Fazer com que as atividades cheguem aos alunos, devido à falta de acesso à internet (Professor 31).

Os alunos terem acesso às atividades. Minha escola é carente, e grande parte não tem acesso. (Professor 35).
}

Embora as tecnologias possam ser uma ferramenta explorada pelos professores, os desafios ainda são grandes para transformar, por exemplo, o celular em ferramenta para estudo. Além das dificuldades de acesso às plataformas de ensino e do grande número de brasileiros sem acesso à internet, acrescentam-se os brasileiros que têm acesso precário à internet, subindo para 70 milhões (SOPRANA, 2020). Há uma maior desigualdade social dos brasileiros quando é feito o recorte das classes $\mathrm{D}$ e $\mathrm{E}$. Dos que têm acesso à rede, $85 \%$ utilizam a internet só pelo celular e com pacotes limitados. Além disso, as antenas de celulares devem enviar sinal para 1.500 aparelhos. Nas periferias, esse número pode chegar a 12 vezes mais aparelhos conectados a uma mesma antena, tornando o sinal muito fraco. Mesmo os brasileiros que têm algum acesso à internet enfrentam diversas outras dificuldades, o que muitas vezes torna as aulas digitais inviáveis (AGÊNCIA BRASIL, 2020b).

Em segundo lugar, a valorização de saberes conceituais é outra preocupação dos professores:

\footnotetext{
Maior enfoque nos conteúdos teóricos, pois não é possível trabalhar de forma prática. Os alunos não têm acesso à internet. (Professor 10).

Deixaram de ser práticas e estão exclusivamente teóricas. (Professor 14).

Uma mudança de foco na forma de apresentar o conteúdo para o aluno. A vivência corporal não se faz mais tão presente. (Professor 27).
}

A Educação Física vem se constituindo como uma disciplina que valoriza e enfatiza os saberes corporais. Esses saberes foram destaque nos PCNs (BRASIL, 1997; 1998), estão presentes no Referencial Curricular do Rio Grande (RIO GRANDE DO SUL, 2009) e têm grande protagonismo na BNCC (BRASIL, 2018). Na BNCC, 
a Educação Física propõe o acesso de crianças, jovens e adultos a um universo que compreende os saberes corporais, "experiências estéticas, emotivas, lúdicas e agonistas, que se inscrevem, mas não se restringem, à racionalidade típica dos saberes científicos que, comumente, orienta as práticas pedagógicas na escola" (BRASIL, 2018, p. 213).

A constituição da Educação Física Escolar no Brasil foi proeminentemente da ordem de saberes corporais, estabelecendo-se como uma referência aos docentes e à sociedade. Não se afirma que esses são saberes mais importantes do que outros, mas se alerta que são parte da construção cultural e social, sendo responsabilidade da Educação Física ensiná-los aos sujeitos nas escolas.

Em terceiro lugar, há a falta de interação com os alunos:

\footnotetext{
A maior dificuldade foi repensar meus objetivos, já que minhas aulas eram pautadas pela construção de uma afetividade através do movimento e do contato corporal. (Professor 37).

Falar para uma câmera, não ter contato direto com os alunos, planejar e editar os vídeos. (Professor 32).

$\mathrm{Na}$ escola, com a Educação Infantil, trabalhamos bastante as relações entre as crianças, a cooperação, o coletivo. Com aulas remotas, as atividades se tornam individuais. (Professor 9).

Deixaram de ter a socialização que o esporte coletivo e as aulas de Educação Física na escola proporcionam. (Professor 15).
}

A falta de interação evidencia outra preocupação. Se considerarmos que os saberes são de ordens conceituais, corporais e atitudinais, sendo este último estabelecido a partir da interação entre os sujeitos, a falta do contato esmaece a construção desse conhecimento. Nos PCNs, são apresentados como os que permeiam todo o conhecimento escolar, entendendo-se que a escola é um contexto socializador, gerador de atitudes relativas ao conhecimento, ao professor, aos colegas, às disciplinas, às tarefas e à sociedade.

Já na BNCC (2018), competência recebe um sentido amplo, e são empregados conceitos como a mobilização de conhecimentos - conceitos e procedimentos -, habilidades - práticas, cognitivas e socioemocionais -, atitudes e valores "para resolver demandas complexas da vida cotidiana, do pleno exercício da cidadania e do mundo do trabalho". Dentre as competências gerais propostas pela BNCC (2018), destaca-se: "valorizar e fruir as diversas manifestações artísticas e culturais, das locais às mundiais, e também participar de práticas diversificadas da produção artístico-cultural". Tendo em conta a organização dos saberes, os atitudinais não foram pensados e estruturados nas condições atuais. O que é da ordem da socialização, da convivência com o outro, da compreensão de limites - do que a escola, como a conhecemos, tem se encarregado -, parece não ter lugar neste momento.

\subsection{ENFRENTAMENTOS E POSSIBILIDADES}

Nesta seção, são enfatizadas as possibilidades que aparecem para enfrentar essa situação a partir de três ordens: reorganização dos planejamentos, Educação Física para viver o distanciamento social e relações de afeto. 
A respeito da reorganização dos planejamentos, é preciso voltar a atenção a este ponto. Elemento importante da ação pedagógica, o planejamento envolve múltiplos aspectos do processo educativo. Como destaca Vasconcelos: "[...] planejamento é processo, contínuo e dinâmico, de reflexão, tomada de decisão, colocação em prática e acompanhamento. [...] planejamento, enquanto processo é permanente. O plano, enquanto produto é provisório" (VASCONCELOS,1999, p. 80).

A ideia de processo e de provisoriedade que perpassa o planejamento é algo que tem estado presente nas reflexões. A novidade que temos é o contexto do trabalho a ser planejado e desenvolvido. É preciso reconhecer que não foi realizada preparação para trabalhar no modo remoto. Até este momento, identificado como emergencial, o planejamento tinha como foco um ensino presencial, situação que assume outra configuração no distanciamento, desafiando a docência a reinventarse. Tal questão perpassa as falas dos sujeitos:

A principal mudança foi a reinvenção dos professores, através da adaptação de planejamento proposto no início do ano, adaptações de conteúdos, maneira como são transmitidos e desenvolvidos. (Professor 43).

A novidade remete a outros conteúdos, outras estratégias de trabalho. As reflexões de Bossle e Wittizorecki ${ }^{5}$ instigam a indagar se, a partir da pandemia, poderá emergir um novo contrato didático para a Educação Física Escolar. O desafio seria tratar o planejamento como uma ação coletiva, participativa e solidária, em uma artesania compartilhada entre professores, familiares e estudantes, ao encontro das novas possibilidades que estão sendo gestadas no ineditismo destes tempos.

Em relação ao ponto Educação Física para viver o distanciamento social, ressalta-se o fato de que saberes da ordem de disciplinas que, por vezes, ficaram à margem das organizações curriculares trazem suporte importante para estes tempos de distanciamento social. Estamos falando da Arte, da Música, do Teatro, da Filosofia, da Sociologia e da Educação Física. Sobre isso, afirmam os professores:

As aulas de EF ganharam maior importância, pois é estressante ficar dentro de casa parado, e vejo que há muita procura dos alunos em se mexer. Então, creio que a EF está ganhando um baita espaço! (Professor 32).

O ganho de espaço pela Educação Física pode ser debatido sob inúmeros enfoques. Opta-se por discuti-lo à luz da reafirmação do processo de ensino e de aprendizagem como desafio para conjugar conhecimento escolar com prática de vida. Neste momento em que a escola invade as casas, mesmo considerando o posicionamento de que a casa não é a escola, cabe refletir sobre a importância dos conhecimentos escolares como passíveis de um reencontro com a vida. Segundo Franco,

Sabe-se da circunstancialidade dos conteúdos de aprendizagem que são considerados em um determinado momento pedagógico. No entanto, a expectativa é a de que esta seleção de conteúdos e práticas conexas seja cada vez mais ampliada e qualitativamente diferenciada, de forma que o ensino seja cada vez mais ensino/leitura do mundo e cada vez menos ensino/informação do mundo (FRANCO, 2012, p. 171).

\footnotetext{
5 Fabiano Bossle e Elisandro Wittizorecki, em suas participações como palestrantes no Curso de extensão online Educação Física na Educação Básica: diálogos e possibilidades - IV edição. Disponíveis em: https://www.facebook. com/GEDAEF/
} 
Considera-se que há uma reinvenção no modo como o ensino e a aprendizagem vinham sendo propostos de dentro e para dentro da escola. Resta olhar para o que está sendo reorganizado, recriado, transmutado - para, quem sabe, reescrever uma prática pedagógica em que Educação Física possa ser invadida, contaminada pelo cotidiano e pela existência.

O terceiro enfrentamento foi nomeado como relações de afeto. Importante marcar que os docentes, de um modo geral, apostam na afetividade desenvolvida nas aulas de Educação Física para superar os desafios impostos pelas aulas remotas.

Reforço da empatia. Percebo as dificuldades que eu tenho como professor em ter que ficar de quarentena e imagino o que os alunos também estejam passando. Acredito que a Educação Física pode ser uma válvula de escape nesse momento, oferecendo atividades mais dinâmicas e prazerosas, mesmo sendo a distância. (Professor 33).

O desafio de oferecer atividades dinâmicas e prazerosas, mesmo a distância, alia-se ao resgate dos vínculos de afeto. Carvalho (2012) convida a refletir sobre currículo e redes sociais, evidenciando a importância da rede como dispositivo que permite estabelecer uma interação "material" e "imaterial" que nos permita uma imbricação com o mundo, com as pessoas e com o cotidiano.

[...] o importante é pensar não na tecnologia em si, como prótese ou extensão, mas como um processo contínuo de delegação e distribuição das atividades cognitivas, linguísticas e afetivas que formam uma rede com os diversos 'dispositivos' não humanos. Em outras palavras, uma rede de aprendizado, de circulação da informação, da linguagem e dos afetos, que permite resolver de forma praticoteórica o problema da presença e da ausência em um lugar (CARVALHO, 2012, p. 197).

A expressão praticoteórica é usada intencionalmente para demarcar o aspecto de conjunção que perpassa a ideia e, de certa forma, resgata a dimensão de interação e ajuda a enaltecer as possibilidades relacionais que se busca estabelecer, mesmo a distância.

\section{CONSIDERAÇÕES}

A partir do propósito de compreender o modo como a Educação Física Escolar se posicionou nas aulas remotas em tempos de distanciamento social frente à pandemia de Covid-19, afirma-se que a Educação Física acompanhou as demais atividades das escolas. Contudo, muitas dificuldades foram evidenciadas: entraves nas relações entre famílias, alunos e professores; a dificuldade e falta de acesso e de conhecimento sobre como operar com as tecnologias da informação e da comunicação; a valorização de saberes conceituais em detrimento de saberes corporais e de saberes atitudinais; e a falta de interação entre os sujeitos. Apesar disso, percebemos que os docentes optaram por enfrentar as situações adversas por meio da reorganização dos seus planejamentos, da valorização da Educação Física como componente curricular importante neste momento e da ênfase nas relações de afeto.

Porém, é preciso dizer que as práticas vividas neste momento são muito distintas das vivenciadas. O trabalho em conjunto - de troca, de vibração em grupo, de aprendizagens coletivas - foi deslocado para um trabalho voltado para 
o individual. A espontaneidade do contato docente e discente foi substituída pela edição dos vídeos. A voz do professor, pela leitura solitária dos textos. O coletivo, pelo individual. O jogo, o esporte, a brincadeira, por gestos isolados. O barulho da turma foi trocado pelos microfones desligados. A correria da escola perdeu espaço para as câmeras fechadas. O espaço da escola foi substituído pelo espaço da casa. O tempo do professor nem sempre é o tempo do aluno. São outras práticas.

É preciso compreender que se trata de outra coisa, vive-se outro tempo. É um período emergencial, de pandemia, em que é preciso sobreviver. Não há uma transformação da escola, nem da Educação Física Escolar nem adaptação ou reinvenção. Estão sendo vividas outras práticas. E, nessa medida, o currículo também é outro. Os efeitos nos sujeitos e nas instituições também será outro. É um processo de ensino planejado e executado por docentes, instituições, alunos e famílias, mas bastante distinto do precedente. Para além do bem e do mal e de julgar como certo ou errado, compreende-se que estamos envolvidos em um processo distinto, mas que abre uma oportunidade de avaliar o que tínhamos para planejar como queremos a Educação Física Escolar.

\section{REFERÊNCIAS}

AGÊNCIA BRASIL (BRASIL). Pesquisa Nacional por Amostra de Domicílios Contínua. 2020a Disponível em: https://agenciabrasil.ebc.com.br/economia/noticia/2020-04/um-emcada-quatro-brasileiros-nao-tem-acesso-internet . Acesso em: 29 abr. 2020.

AGÊNCIA BRASIL (BRASIL). Pesquisa Nacional por Amostra de Domicílios Contínua. 2020b. Disponível em: https://agenciabrasil.ebc.com.br/economia/noticia/2020-04/celular-eo-principal-meio-de-acesso-internet-no-pais. Acesso em: 29 abr. 2020.

BRASIL. Ministério da Educação. Base Nacional Comum Curricular: Ensino Médio. Brasília: MEC, [2018]. Disponível em: http://basenacionalcomum.mec.gov.br/images/BNCC El EF 110518 versaofinal site.pdf Acesso em: 27 mai. 2020.

BRASIL, Secretaria de Educação Fundamental. Parâmetros curriculares nacionais: introdução aos parâmetros curriculares nacionais. Brasília: MEC/SEF, 1997.

BRASIL. Secretaria de Educação Fundamental. Parâmetros curriculares nacionais: introdução aos parâmetros curriculares nacionais. Brasília: MEC/SEM, 1998.

BRASIL. [Constituição (1937)]. Constituição dos Estados Unidos do Brasil de 1937. Disponível em: https://www2.camara.leg.br/legin/fed/consti/1930-1939/constituicao-3509310-novembro-1937-532849-publicacaooriginal-15246-pl.html Acesso em: 15 jan. 2020.

BRASIL. Lei $n^{\circ} 5.692$ de 11 de agosto de 1971. Fixa as Diretrizes e Bases para o ensino de $1^{\circ}$ e $2^{\circ}$ graus, e dá outras providências. Brasília, 1971a. Disponível em: http://www2. camara.leg.br/legin/fed/lei/1970-1979/lei-5692-11-agosto-1971-357752-publicacaooriginal-1pl.html Acesso em: 12 mai. 2020.

BRASIL. Decreto 69.450 de $1^{\circ}$ de novembro de 1971. Brasília, 1971b. Disponível em: http://www.planalto.gov.br/ccivil_03/decreto/d69450.htm Acesso em: 20 jul. 2020. 
BRASIL. Lei n 9.394, de 20 de dezembro de 1996. Lei de Diretrizes e Bases da Educação Nacional. Brasília: Presidência da República, 1996.

BRASIL. Lei n 13.415, de 16 de fevereiro de 2017. Brasília: Presidência da República, 2017.

BRASIL. Medida Provisória $n^{\circ}$ 746, de 22 de setembro de 2016. Brasília: Presidência da República, 2016.

CARVALHO, Janete Magalhães. Práticas pedagógicas nas múltiplas redes educativas que atravessam os Currículos. In: LIBÂNEO, José Carlos; ALVES, Nilda (org.). Temas de Pedagogia: diálogos entre Didática e Currículo. São Paulo: Cortez, 2012.

CASTELLANI FILHO, Lino et al. Metodologia do ensino da educação física. São Paulo: Cortez, 1992.

CASTRO, Maria Helena G. Secretária executiva do MEC esclarece pontos do Novo Ensino Médio. Entrevistada por: Laís Semis. Nova Escola, 3 jan. 2017. Disponível em: https:// novaescola.org. br/conteudo/4702/secretaria-executiva-do-mec-esclarece-pontos-do-novoensino-medio\# Acesso em: 10 de julho de 2020.

FRANCO, Maria Amélia Santoro. Práticas pedagógicas nas múltiplas redes educativas. In: LIBÂNEO, José Carlos; ALVES, Nilda (org.). Temas de Pedagogia: diálogos entre didática e currículo. São Paulo: Cortez, 2012.

GATTI, Bernadete; ANDRÉ, Marli. A relevância dos métodos de pesquisa qualitativa em educação no Brasil. In: WELLER, Wivian e PFAFF, Nicolle. Metodologias da pesquisa qualitativa em Educação: teoria e prática. Petrópolis, RJ: Vozes, 2013.

MACHADO, Roseli Belmonte. A inclusão com rede: uma análise de práticas de professores de Educação Física na Contemporaneidade. Tese (Doutorado em Educação), Programa de Pós-Graduação em Educação, Universidade Federal do Rio Grande do Sul, Porto Alegre, RS, 2016.

OLIVEIRA, Dalila Andrade. A reestruturação do trabalho docente: precarização e flexibilização. Educação e Sociedade, v. 25, n.89, p. 1127-1144, set./dez. 2004.

RIO GRANDE DO SUL. Secretária do Estado da Educação. Departamento Pedagógico. Referenciais Curriculares do Estado do Rio Grande do Sul. Porto Alegre: Secretaria de Estado da Educação, 2009.

SARAIVA, Karla; VEIGA-NETO, Alfredo. Modernidade líquida, capitalismo cognitivo e educação contemporânea. Educação e Realidade, v. 34, n. 2, p. 187- 202, mai./ago. 2009.

SILVA, Tomaz Tadeu da. "Adeus às Metanarrativas Educacionais". In: SILVA, Tomaz Tadeu da. (org.). O Sujeito da Educação: estudos foucaultianos. Petrópolis: Vozes, 1994. p. 247258.

SILVA, Tomaz Tadeu. Documentos de Identidade. Belo Horizonte: Autêntica, 2001.

SOPRANA, Paula. Brasil tem cerca de 70 milhões de pessoas com acesso de internet precário ou inexistente. Folha de S. Paulo, São Paulo: FSP, 2020. Disponível em: https:// www1.folha.uol.com.br/mercado/2020/05/cerca-de-70-milhoes-no-brasil-tem-acessoprecario-a-internet-na-pandemia.shtml . Acesso em: 19 mai. 2020.

VASCONCELOS, Celso dos Santos. Planejamento: Projeto de ensino-aprendizagem e projeto político pedagógico. São Paulo: Libertad, 1999. 
VEIGA-NETO, Alfredo. Currículo na Contemporaneidade: internacionalização e contextos locais. In: Colóquio sobre Questões Curriculares, 11 e Colóquio LusoBrasileiro de Currículo, 6. Anais... Braga: Universidade do Minho, 2014. Disponível em: http://livrozilla.com/doc/1150210/curr\%C3\%ADculo-na-contemporaneidade-internacionaliza\%C3\%A7\%C3\%A3o-e-con... Acesso em: 3 nov. 2020.

VEYNE, Paul. Como se escreve a História: Foucault revoluciona a história. Brasília: UNB, 1995. 
Abstract: In 2020, the COVID-19 Pandemic hit the world. Measures to tackle it included social distancing, causing schools to close in mid-March 2020. Face-toface classes turned into online ones. Considering this, we aimed at understanding the position taken by Physical Education in the online class scenario of the Brazilian state of Rio Grande do Sul. We conducted qualitative research with school teachers working with online Physical Education lessons. The instrument was a 20-item questionnaire sent by email. Physical Education followed the activities produced by schools, but we found changes in the way of conducting lessons and highlighted challenges for teachers' work and effects on the curriculum.

Keywords: Physical Education. Coronavirus infection. School teachers. Curriculum.

Resumen: El año 2020 trajo la pandemia de COVID-19, que alcanzó a todo el mundo. Las medidas para contener la propagación incluyeron la distancia social, lo que provocó, a mediados de marzo de 2020, el cierre de las escuelas, lo que llevó a que las clases que eran presenciales pasaran a ser remotas. A partir de esto, nuestro objetivo ha sido comprender cómo se ha posicionado la Educación Física, en Rio Grande do Sul, en el escenario de las clases remotas. Con este fin, realizamos una investigación cualitativa con profesores de escuelas de Rio Grande do Sul que están trabajando con Educación Física a través de la enseñanza remota. El instrumento fue un cuestionario con 20 preguntas enviado por correo electrónico. Constatamos que la Educación Física acompañó las actividades producidas por las escuelas, pero identificamos alteraciones en la forma de conducción y destacamos los desafíos del trabajo de los docentes y sus efectos en el plan de estudios.

Palabras clave: Educación Física. Infecciones por coronavirus. Profesores. Plan de estudios. 


\section{LICENÇA DE USO}

Este é um artigo publicado em acesso aberto (Open Access) sob a licença Creative Commons Atribuição 4.0 Internacional (CC BY 4.0), que permite uso, distribuição e reprodução em qualquer meio, desde que o trabalho original seja corretamente citado. Mais informações em: http://creativecommons.org/licenses/by/4.0

\section{CONFLITO DE INTERESSES}

Os autores declararam que não há conflito de interesses neste trabalho.

\section{CONTRIBUIÇÕES AUTORAIS}

Roseli Belmonte Machado: Conceptualização; Análise Formal; Metodologia; Administração do Projeto; Supervisão; Validação; Escrita - análise e edição;

Denise Grosso da Fonseca: Conceptualização; Análise Formal; Supervisão; Validação; Escrita - análise e edição;

Nicolas Fernandes: Curadoria de Dados; Investigação; Escrita - rascunho original; Análise Formal;

Francine Muniz Medeiros: Curadoria de Dados; Investigação; Escrita - rascunho original; Análise Formal.

\section{FINANCIAMENTO}

O presente trabalho foi realizado sem qualquer apoio financeiro.

\section{ÉTICA EM PESQUISA}

O estudo foi realizado mediante análise e aprovação do projeto de pesquisa $n$. 1.123.640, pelo Comitê de Ética da UFRGS. A autoria declarou ter contemplado todos os procedimentos éticos que constam na normativa Guia de Integridade em Pesquisa Científica da Universidade Federal do Rio Grande do Sul. Disponível em: https://www.ufrgs.br/propesq1/propesq/wp-content/uploads/2020/06/guia-paraintegridade-em-pesquisa-cientifica.pdf

\section{COMO REFERENCIAR}

MACHADO, Roseli Belmonte; FONSECA, Denise Grosso da; MEDEIROS, Francine Muniz; FERNANDES, Nícolas. Educação física escolar em tempos de distanciamento social: panorama, desafios e enfrentamentos curriculares. Movimento, v.26, p. e26081, jan./dez. 2020. Disponível em. Acesso em: https:// seer.ufrgs.br/Movimento/article/view/106233. Acesso em: [dia] [mês abreviado]. [ano]. DOI: https://doi.org/10.22456/1982-8918.106233

\section{RESPONSABILIBADE EDITORIAL}

Alex Branco Fraga*, Elisandro Schultz Wittizorecki*, Ivone Job*, Mauro Myskiw*, Raquel da Silveira*

*Universidade Federal do Rio Grande do Sul, Escola de Educação Física, Fisioterapia e Dança, Porto Alegre, RS, Brasil 